Journal of Mathematics and Statistics 6 (3): 372-380, 2010

ISSN 1549-3644

(C) 2010 Science Publications

\title{
Time Series Analysis of Rainfall and Temperature Interactions in Coastal Catchments
}

\author{
${ }^{1}$ Gurudeo Anand Tularam and ${ }^{2}$ Mahbub Ilahee \\ ${ }^{1}$ Department of Mathematics and Statistics, \\ Faculty of Science Environment Engineering and Technology, \\ School of Environment, Griffith University, Australia \\ ${ }^{2}$ School of Environment, Griffith University, Australia
}

\begin{abstract}
Problem statement: As a result of climate change more work is now being done on climate indices such as SOI, rainfall, temperature and so on. The research concerning rainfall and temperature variations in coastal tropical and subtropical catchments as noted by the dated references in this study shows a lack of attention. The authors examined long term data from coastal areas of Queensland. Australian climate is highly variable making the identification of trends or interactions between rainfall and temperature difficult to discern from background variation. Due to the lack of attention in the past, this study examined the relationships between rainfall, temperature, minimum temperature and maximum temperature as well as over time using time series methods. In particular, the study examined whether a cyclic nature existed in the data sets and whether a simple trend relationship between rainfall and temperature existed. To examine autocorrelation and seasonality ARIMA models were also investigated. Approach: A large data set involving more that 50 years of rainfall and temperature data were examined using spectral analysis, time series analysis-ARIMA methodology to analyse climatic trends and interactions. Fourier analysis, linear regression and ARIMA based time series models were used to analyze the large data sets using Matlab, SPSS and SAS programs. Results: The rainfall data was variable and appeared seasonal while the temperature data appeared stationary. Interestingly, spectral analysis showed variations in rainfall and temperature over 50-60 years but the results showed that rainfall and temperature varied coherently, with a cycle of about 2-3 years. An inverse relationship in trend was noted between rainfall and daily temperature range using linear regression among the variables. The ARIMA models showed autocorrelation and seasonality providing time series models. Conclusion/Recommendations: There is a cyclic pattern noted in both the rainfall and temperature time series and a cycle of about 3 years in the rainfall and temperature data sets suggesting a coherent variance in the relationship. This is an interesting finding suggesting a cyclic nature of large rainfall events over time and has been confirmed by the recent large rainfalls events in 2009-10. Linear regression showed an inverse relationship in trend between rainfall and temperature range only even though the $r$ value was around 0.27 . The autocorrelation in the data appears to have caused the low $r$ and ARIMA methods was used giving time series models for each series allowing for autocorrelation and seasonality. This study on rainfall and temperature is valuable contribution to the lack of research noted particularly in Queensland as noted in the dated references found; also contributing to the climate change debate forcing it on the cautious side. Further work involving multivariate and dynamic conditional correlation methods may provide further insights regarding the relationships between rainfall and temperature. More climatic indices such as SOI may be used in future studies.
\end{abstract}

Key words: Time series, ARIMA model, periodogram, spectral analysis, Fourier

\section{INTRODUCTION}

There is little doubt that Australia has always had a highly variable climate and that Australians are still learning to adapt to it (Tularam and Ilahee, 2010). Most of Australia was settled before long-term climate data were collected. The result is that agricultural and urban land use patterns were fixed well before there was any

Corresponding Author: Gurudeo Anand Tularam, Department of Mathematics and Statistics,

Faculty of Science Environment Engineering and Technology, School of Environment,

Griffith University, Australia 
understanding that Australia's climate is highly variable, with a high occurrence of widespread extreme wet and dry years. For example, eastern Australia has experienced several sequences of wet years since the late 1880s (early 1890s, 1916-18, early 1920s, mid-1950s, early 1970s and late 1990s). Dry conditions in various rural regions followed these wet sequences (1896-1902, 1919-20, 1926-31, mid-1960s, early 1980s and 2001 to present) (Mantua and Hare, 2002; Power et al., 1999).

Some areas have recently experienced eight consecutive years of below-average rainfall (Bureau of Meteorology, 2002). Long-term records show that dry sequences are not unusual. For example, Lake George in New South Wales showed a 17-year dry spell in the 1930s and 1940s (Singh and Geissler, 1985). More recent data show the trend may be continuing, but a statistical conclusion cannot be reached.

The purpose of the present study is twofold: (i) analysis of the eastern Queensland climate variation or change and (ii) study the relationship between temperature and rainfall variations in eastern Queensland catchments (Queensland encompasses 26 per cent of the land area of Australia). Although Queensland rainfall (Lough, 1991; 1993) and temperatures (Lough, 1995) were examined previously using a relatively large number of stations, such analyses however were based on data up to the 80's (as noted in references). The present study updates not only the data but also provides more in depth analysis of the relationship and the cyclic nature of rainfall and temperature.

Background literature: Although drought is seen as an extreme event, long periods of low rainfall are common in Australia. The most recent drought story begins in 2001-02, when drought began in areas of south-western Queensland in 2002-03. Extreme drought occurred across much of eastern Australia, further exacerbating drought conditions in those areas (McKeon and Hall, 2000; McKeon et al., 2004; Sivakumar and Ndegwa, 2007). Following average conditions in 2003-04, severe drought returned in many regions in 2004-05. For many regions of Australia, the overall five-year period from April 2000 to March 2005 represents extremely low rainfall compared to the historical records commencing in 1890.

A similar but more cautionary story emerges from an analysis of the last 40 years of rainfall records. In much of Australia, this recent drought started after a sequence of above-average years of rainfall from the second half of 1998 to the first half of 2001. Central coastal Queensland and south-west Western Australia had already experienced drier conditions for at least 15 years. For example, eastern Australia received significantly less rainfall during the three years from 2002-2005 than during 1961-90 (the current international standard reference period). Coastal areas experienced the greatest rainfall deficits (the difference between actual rainfall in a year and the long-term average). In contrast, during the same 2002-05 period, rainfall in the north of the Northern Territory and in parts of north-western Western Australia was significantly greater than that experienced from 1961-90 (Bureau of Meteorology, 2005). The recent drought may be unusual in that it has been warmer than previous droughts in the last 50 years (the length of temperature records).

The enhanced greenhouse scenario suggests that temperatures in Australia may rise by $1-0-2^{\circ} \mathrm{C}$, summer rainfall may increase and the frequency of high rainfall and flooding events may also increase (Whetton et al., 1993; 1994). Hence, there is growing awareness of the possible consequences of global climate change. High rainfall may be a blessing to Australia but this has not been noted in recent times. Indeed, such a scenario is difficult to grasp for those living in Queensland and parts of eastern Australia that have been subject to a 'severe and persistent' drought since 1991 (Bureau of Meteorology, 1995).

Observational studies, however, lend some support to these projected changes. Over the period 1910 to 1988, summer rainfall appears to have increased over much of eastern Australia (Nicholls and Lavery, 1992). This increase occurred rather abruptly around 1950, confirming earlier findings (Pittock, 1975). There is also evidence that annual rainfall intensity and the frequency of heavy rainfall events have increased over tropical Australia over the period 1910-1989 (Suppiah and Hennessy, 1996). Observational studies also provide evidence of temperature increases over Australia (Jones et al., 1990; Plummer, 1991).

Temperatures have been equally variable. The average temperature across Australia has risen by $0.82^{\circ} \mathrm{C}$ between 1910 and 2004 with much of the warming occurring in the second half of the twentieth century. The warmest year on record is 2005. Until 2004, the warmest year had been 1998. These temperature changes have been greater for minimum than maximum temperatures with a consequent decline in the Daily Temperature Range (DTR) in recent decades (Plummer et al., 1995), matching trends in DTR found in other parts of the world (Karl et al., 1993). Some of these trends in Australian climate over recent decades have also been identified in climate regions of the south-west Pacific (Salinger et al., 1995).

While there has been research on rainfall and temperature interactions the majority of them were conducted in earlier times and therefore note able to 
benefit from the large changes that may have occurred in recent times when climate change issue has come to the fore. Not only that, the literature review showed little work has been done in coastal Queensland on this area given that climate change has been a major driving force for research. As noted earlier, this study uses a updated dataset and time series techniques to further understand the relationship between rainfall and temperature in coastal Queensland (Charnsethikul, 2007).

Data sources: The data used in this research was obtained from the Australian Bureau of Meteorology and incorporated 50-60 years of rainfall and temperature for Brisbane, Rockhampton, Mackay and Townsville (Fig. 1). These four stations were selected as they had rainfall and temperature records extending back to at least 1950 and were located to give as extensive coverage of Queensland as possible. The choice of station was also based on the quality of record and that the monthly station rainfall and minimum and maximum temperatures were reported regularly in the Monthly Weather Review, Queensland (published by the Australian Bureau of Meteorology). This allows the data series to be regularly and promptly updated. From this data it can be determined how unusual the recent drought in Queensland has been and how temperature change and rainfall interact in the catchment.

It is increasingly clear that the last 50 years of experience with rainfall patterns is not a sufficient time span to plan and design an adequate response to climate variability and change. The best data are for rainfall, which can be measured in terms of the amount of rain falling in a $24 \mathrm{~h}$ period. Australia's rainfall is so variable over time that the trends in extreme rainfall during 1910-2005 differ from those during 1970-2005. The complete record of the seasonal rainfall time series for each station was ranked from 1 to $\mathrm{n}$, where $\mathrm{n}$ was the total number of years.

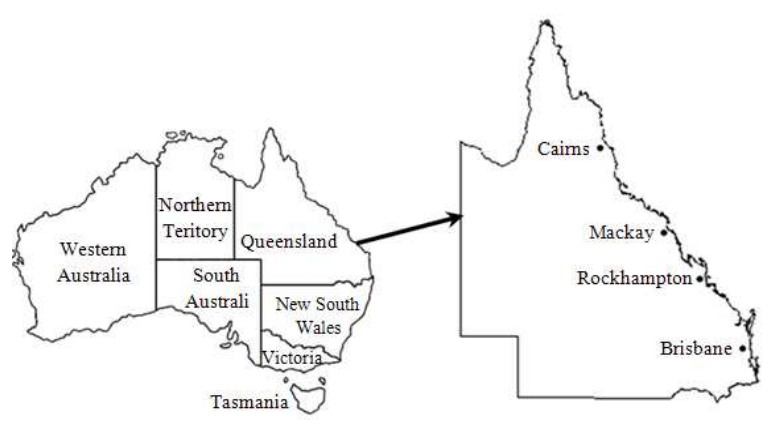

Fig. 1: Locations of 4 monitoring stations

\section{MATERIALS AND METHODS}

Four Queensland catchments were selected from various parts of eastern Queensland (Fig. 1) to observe the interactions between changes in temperature and rainfall. The catchment average rainfall data is based on the available daily rainfall data.

Spectral analysis: This research uses the Fast Fourier Transform (FFT) function to analyse the variations in rainfall and temperature activity over the last $50-60$ years in eastern Queensland. $\mathrm{Y}=\mathrm{fft}(\mathrm{X})$ returns the Discrete Fourier Transform (DFT) of vector X, computed with a FFT algorithm. If $\mathrm{X}$ is a matrix, fft returns the Fourier transform of each column of the matrix. If $\mathrm{X}$ is a multidimensional array, $\mathrm{fft}$ operates on the first non singleton dimension. $Y=f f t(X, n)$ returns the n-point DFT. If the length of $X$ is less than $\mathrm{n}, \mathrm{X}$ is padded with trailing zeros to length $\mathrm{n}$. If the length of $X$ is greater than $n$, the sequence $X$ is truncated. If $X$ is a matrix the length of then the columns of $\mathrm{X}$ are adjusted in the same manner. $\mathrm{Y}=$ $\mathrm{fft}(\mathrm{X},[], \operatorname{dim})$ and $\mathrm{Y}=\mathrm{fft}(\mathrm{X}, \mathrm{n} \operatorname{dim})$ applies the FFT operation across the dimension dim.

The functions $\mathrm{X}=\mathrm{fft}(\mathrm{x})$ and $\mathrm{x}=$ ifft $(\mathrm{X})$ implement the transform and inverse transform pair given for vectors of length $\mathrm{N}$ in Eq. 1 below:

$$
\begin{aligned}
& X(k)=\sum_{j=1}^{N} x(j) \omega_{N}^{(j-1)(k-1)} \\
& x(j)=\sum_{k=1}^{N} X(k) \omega_{N}^{-(j-1)(k-1)} \\
& \text { where } \\
& \omega_{N}^{-2 \pi i / N} \text { is the } N^{\text {th }} \text { root of unity }
\end{aligned}
$$

A graph of the distribution of the Fourier coefficients (given by $\mathrm{Y}$ ) in the complex plane is difficult to interpret (Abdullah et al., 2009). Therefore, a more useful way of examining the data in $\mathrm{Y}$ is needed. The complex magnitude squared of $Y$ is called the power and a plot of power versus frequency is a "periodogram". The scale in cycles/year is somewhat inconvenient. In this case, the years/cycle scaled graphs were plotted and the length of one cycle was determined. The power versus period was also estimated for convenience (where period $=1 /$ freq). The cycle length was fixed more precisely by picking out the strongest frequency.

Further, the relationships between temperature and rainfall variations were also investigated using linear regression with ARMA errors, as well as ARIMA methods. All statistical analyses were carried out using codes in SAS, MATLAB and R. 
Linear regression: This example performs a simple linear regression of rainfall on temperature; it produces the same results as PROC REG or another SAS regression procedure. The mathematical form of the model estimated by these statements is

$$
Y_{t}=\mu+\omega_{0} X_{t}+a_{t}
$$

Any number of input variables can be used in a model. For example, the following statements fit a multiple regression of Rainfall on temperature and Southern Oscillation Index (SOI). The mathematical form of the regression model estimated by these statements is:

$$
Y_{t}=\mu+\omega_{1} X_{1 t}+\omega_{2} X_{2 t}+a_{t}
$$

Lagging and differencing input series: One can also difference the time series and thus lag the input series. For example, the following statements in SAS regress the change in rainfall on the change in temperature lagged by one period. The difference of temperature is specified with the CROSSCORR = option and the lag of the change in temperature is specified by the 1 in the INPUT $=$ option:

proc ARIMA data $=\mathrm{a}$; identify var $=$ rainfall $(1)$ crosscorr $=$ temperature $(1)$; estimate input $=(1$ temperature $)$; run

The above estimates the following ARIMA model:

$$
(1-B) Y_{t}=\mu+\omega_{0}(1-B) X_{t-1}+a_{t}
$$

Regression with ARMA errors: This method combines input series with ARMA models for the errors. For example, the following statements regress rainfall on temperature and SOI but with the error term of the regression model (called the noise series in ARIMA modeling terminology) assumed to be an ARMA $(1,1)$ process. Two independent variables in the model with ARMA $(1,1)$ errors can be represented as:

$$
Y_{t}=\mu+\omega_{1} X_{1 t}+\omega_{2} X_{2 t}+\frac{\left(1-\theta_{1} B\right)}{\left(1-\varphi_{1} B\right)} a_{t}
$$

Stationary and input series: The above modeling requires stationary of the time and noise series. If there are no input variables, the response series (after differencing and subtracting the mean) and the noise series are the same. However, whenever there are inputs the noise series is the residual after the effect of the inputs is removed. Indeed, there is no requirement that the input series be stationary. If the inputs are nonstationary, the response series will be non-stationary, even though the noise process might be stationary. When non-stationary input series are used, one can fit the input variables first with no ARMA model for the errors and then consider the stationary of the residuals before identifying an ARMA model for the noise part.

Identifying regression models with ARMA errors: Earlier the ARIMA modeling identification process that uses the autocorrelation function plots produced by the IDENTIFY statement was described. This identification process does not apply when the response series depends on input variables. This is because it is the noise process for which you need to identify an ARIMA model and when input series are involved the response series, adjusted for the mean is no longer an estimate of the noise series. However, if the input series are independent of the noise series, you can use the residuals from the regression model as an estimate of the noise series; then apply the ARIMA modeling identification process to this residual series. This assumes that the noise process is stationary.

In SAS, the IDENTIFY statement includes the NOPRINT option since the autocorrelation plots for the response series are not useful when you know that the response series depends on input series. The first ESTIMATE statement fits the regression model with no model for the noise process. The PLOT option produces plots of the autocorrelation function, inverse autocorrelation function and partial autocorrelation function for the residual series of the regression on temperature and rainfall. By examining the PLOT option output for the residual series, the author can verify that the residual series is stationary and thus identify an ARMA $(1,1)$ model for the noise process. The second ESTIMATE statement fits the final model. Although this discussion addresses regression models, the same remarks apply to identifying an ARIMA model for the noise process in models that include input series with complex transfer functions.

\section{RESULTS}

Climate variation and change: This analysis required a detailed investigation of the daily rainfall and temperature data allowing the researchers to deal with anomalies or less useful information. Figure 2 and 3 respectively show the daily rainfall and temperature data of Brisbane, Rockhampton, Cairns and Mackay. 

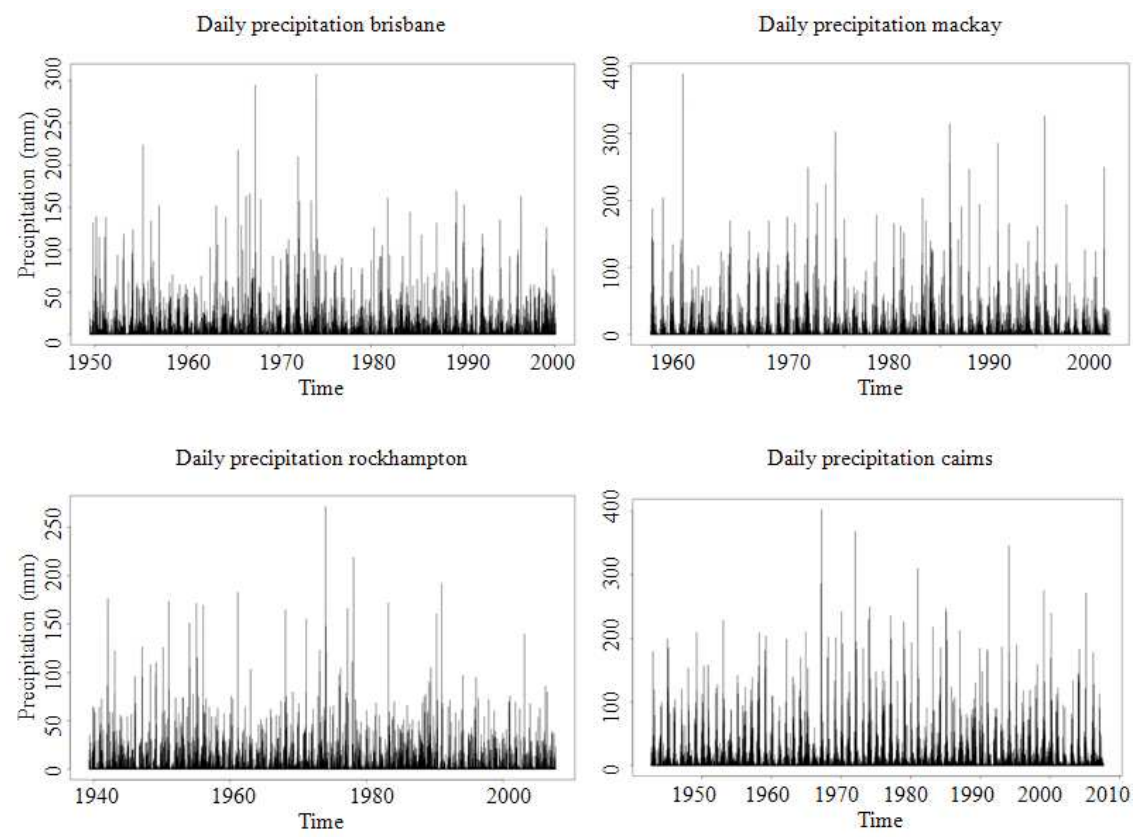

Fig. 2: Daily rainfall of Brisbane, Mackay, Rockhampton and cairns
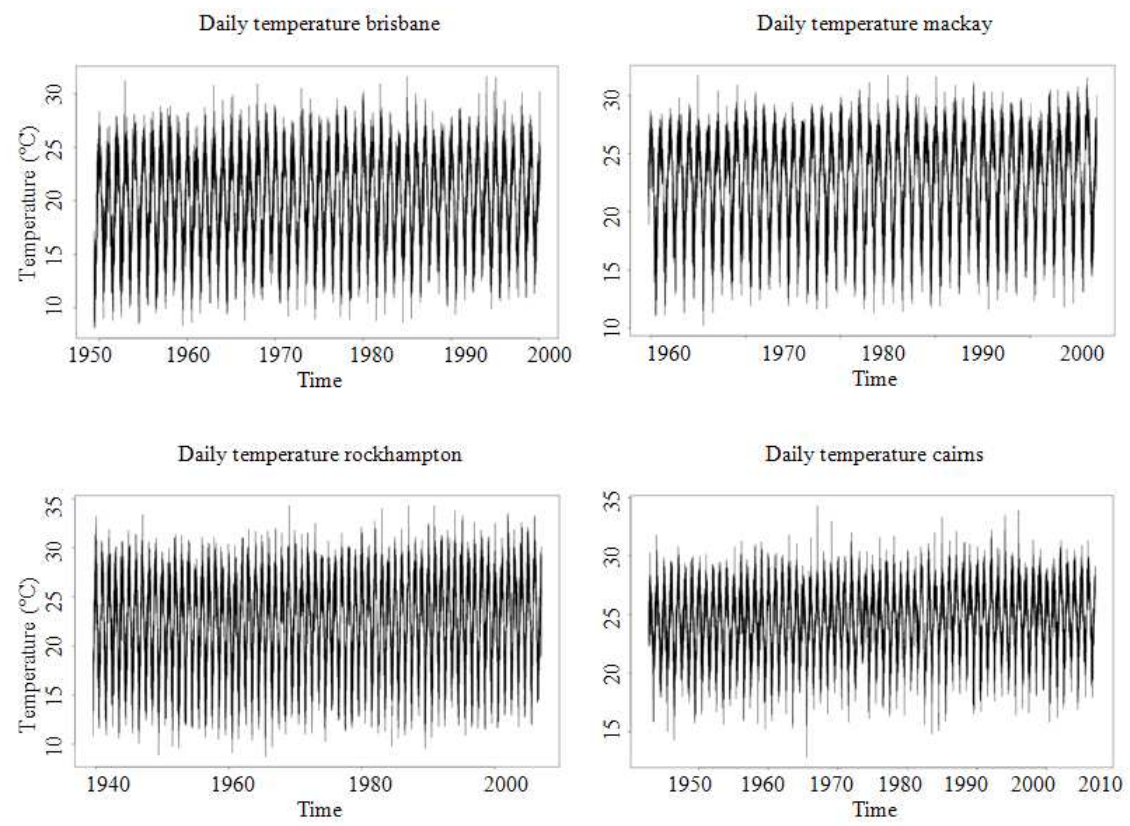

Fig. 3: Daily temperature of Brisbane, Mackay, Rockhampton and Cairns

The Fig. 3 shows daily temperature fluctuations at the same locations.

From the above graphs it was noted that there was no significant trend towards wetter or drier conditions in Queensland within last 60 years either during the summer monsoon or the winter dry season. In contrast, temperatures showed some changes over time. The average and minimum temperatures appear to have increased in both summer and winter and this was accompanied by a significant decrease in the Daily Temperature Range (DTR) (Fig. 4). 

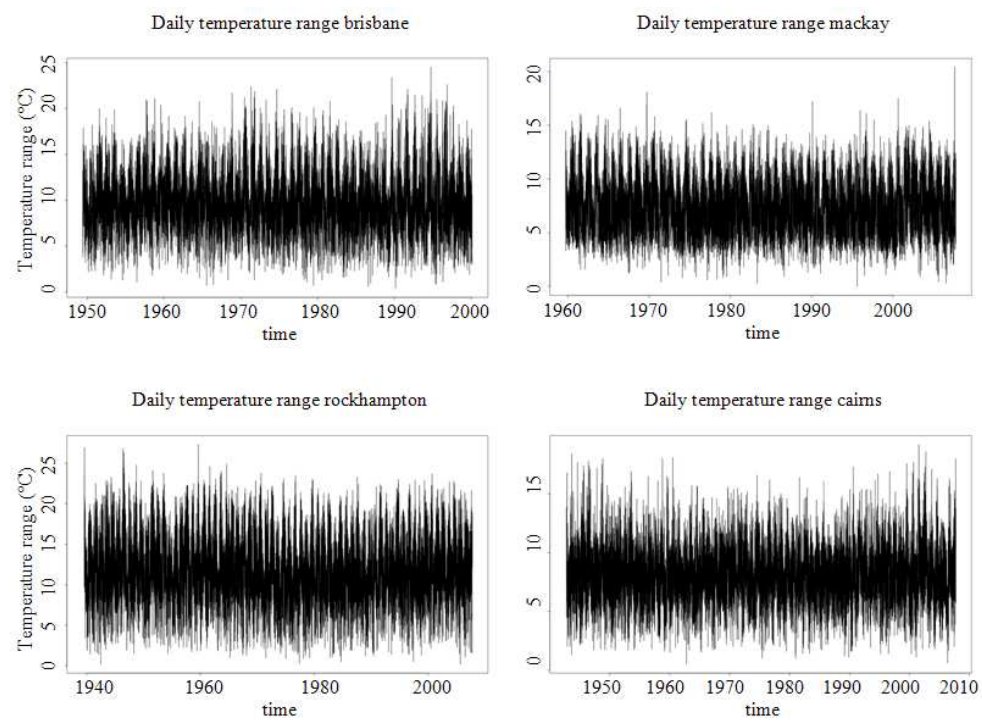

Fig. 4: Daily temperature range of Brisbane, Mackay, Rockhampton and Cairns
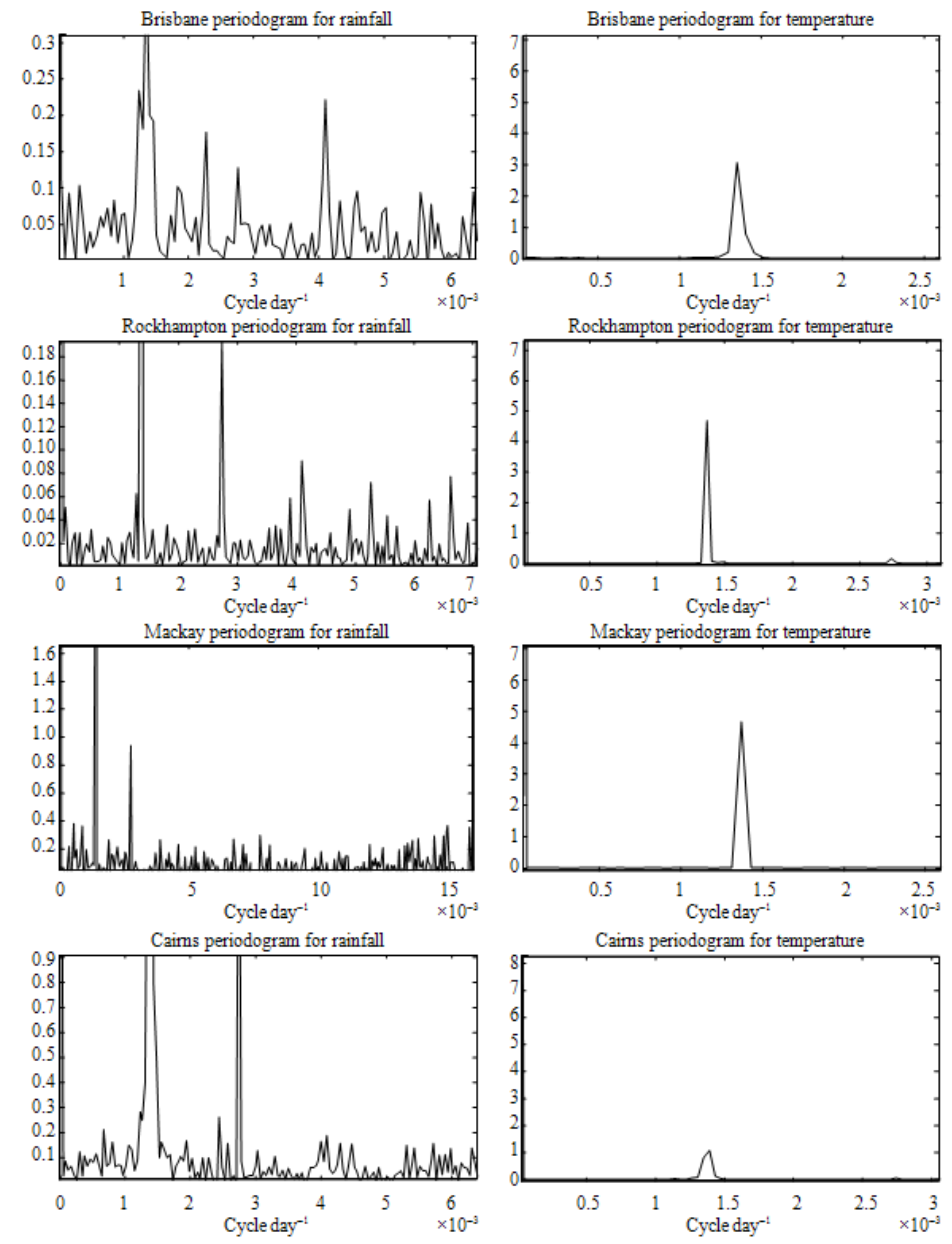

Fig. 5: Daily rainfall and temperature "periodogram" of Brisbane, Rockhampton, Mackay and Cairns 
More detailed data analyses showed changes in average and minimum temperatures and DTR greatest in magnitude in early winter (April-May). The most recent 20 -and 30 year periods suggested that, overall, the highest minimum and average temperatures and lowest DTR over the period since 1950 . There was some weak indication that temperatures were less extreme in 1994 and 1995, but there was insufficient data to assess whether this represented a reversal of the major temperature trends.

Relationship between rainfall and temperature variations: Spectral analysis was used to analyse the relationship between daily rainfall and temperature for Queensland. Essentially, long term data can be characterized by major variation frequencies and this is clearly shown in the following graphs. Once identified, the frequencies were changed to periods, interestingly showing the same period for all locations. Figure 5 shows the periodogram of rainfall and temperature of the four study areas and all four areas show a cycle of 2.2 years (2-3 years) in both rainfall and temperature time series. The left side figure refers to rainfall and the right side to temperature for each of the respective locations.

Cairns: All peaks were clearly identified and all the peaks are not shown in the figures; the leftmost peaks were highest in each case but as noted above, all of them suggested a cycle of 2-3 years approximately.

The trend or linear regression analysis showed that rather than the daily temperature, DTR (daily temperature range) was related to rainfall; although not shown here, this was evident in both summer and winter periods as can be noted in the figures. For each site, an inverse relationship linear relationships exists, with a level of significance of $\mathrm{p}<2.2 \times 10^{-16}$ Eq. 6 :

Brisbane: Rainfall $=12.7287-0.9754 *$ DTR

Rockhampton : Rainfall $=9.3726-0.6118 *$ DTR

Mackay $:$ Rainfall $=12.54106-1.1226 *$ DTR

Cairns: Rainfall $=24.42026-2.3070 *$ DTR

The very low $\mathrm{R}^{2}$ values is not uncommon in large data sets (see financial time series with autocorrelations) for significance of the slope is due to the number of elements in the dataset. The calculated F-tests conclude the regressions were significant due to the very large data set (Table 1). The linear regression may be used to detect a trend and to estimate the mean for the slope is significant. While the modeled residuals (Table 2) improve results they are not significantly better than a pure linear regression models (Table 1) or a pure ARIMA model for rainfall for that matter (Table 3 ). The order of ARIMA models were found by minimizing the AIC. The standardized MSE (by the variance of the rainfall) indicates variable rainfall that cannot be caught up by linear regression or ARIMA reasonably.
Table 1: Summary statistics for linear regression models

\begin{tabular}{lllll}
\hline & MSE & $\begin{array}{l}\text { MSE/variance } \\
\text { (rain) }\end{array}$ & $\mathrm{U}$ & $\mathrm{R}^{2}$ \\
\hline Brisbane & 132.43930 & 0.9373 & 1.021309 & 0.06264 \\
Mackay & 251.84890 & 0.9673 & 1.048452 & 0.03269 \\
Rockhampton & 79.86188 & 0.9335 & 1.013224 & 0.06651 \\
Cairns & 306.93400 & 0.9189 & 1.175020 & 0.08105 \\
\hline
\end{tabular}

\begin{tabular}{|c|c|c|c|c|}
\hline & Order of ARIMA & MSE & $\begin{array}{l}\text { MSE/variance } \\
\text { (rain) }\end{array}$ & $\mathrm{U}$ \\
\hline Brisbane & $(1,0,1)$ & 126.05600 & 0.8921 & 1.0041620 \\
\hline Mackay & $(2,0,1)$ & 215.99910 & 0.8296 & 1.0116650 \\
\hline Rockhampton & $\begin{array}{l}(1,1,2)(0,0,2) \\
(\text { Lough, 1993) }\end{array}$ & 75.12171 & 0.8780 & 0.9932205 \\
\hline Cairns & $\begin{array}{l}(3,0,1)(0,0,2) \\
(\text { Lough, 1993) }\end{array}$ & 266.10290 & 0.7967 & 1.0990840 \\
\hline
\end{tabular}

Table 3: Summary statistics for pure ARIMA model

\begin{tabular}{llrll}
\hline & & \multicolumn{3}{l}{ MSE/ } \\
& Order of ARIMA & \multicolumn{1}{c}{ MSE } & variance (rain) & U \\
\hline Brisbane & $(1,0,2)$ & 129.78800 & 0.9185 & 0.9862854 \\
Mackay & $(2,0,3)$ & 214.87290 & 0.8252 & 0.9862627 \\
Rockhampton & $(2,0,2)$ & 77.50004 & 0.9058 & 0.9851872 \\
Cairns & $(3,0,4)(0,0,2)$ & 270.12690 & 0.8087 & 0.9908906 \\
& (Lough, 1993) & & & \\
\hline
\end{tabular}

However, GARCH models studied lead to persistence or errors and therefore not included here. The residuals of ARIMA do not appear to be white noise suggesting that these patterns might be caught up by defining larger seasonal cycles, but this was not attempted in this study and left for future research.

\section{CONCLUSION}

The first goal of the study was to determine whether recent climate variations in Queensland are in anyway unusual in the context of the 50-60 years of rainfall and temperature records. Summer monsoon rainfall in Queensland has been below average during 1980-1990 but this does not appear to be outside the range of variability found over last 60 years. The second goal of this study was to determine if rainfall and temperature variations in Queensland over the past century could be described by relatively simple relationship of trend. Both rainfall and temperature range appeared to vary coherently in the study areas. The relationship found was an inverse one and only with Daily Temperature Range (DTR). The results can be up-dated regularly from now on therefore providing a useful tool for monitoring climate variation and change in this part of Australia. The periodic nature of rainfall and temperature may have important implications for climate change over the years along the coast of Queensland.

More particularly, DTR was noted to be inversely related to Queensland rainfall in both summer and winter. Inter-annually, the lower DTR is associated with higher rainfall and vice versa. The relationship between DTR and Queensland rainfall has been high and stable over the record period. Other 
data analysis not presented showed that summer rainfall variations are related more closely to maximum than minimum temperatures, with higher temperatures associated with lower rainfall. Lower rainfall in winter tends to be linked with higher maximum and lower minimum temperatures. These relationships were relatively stable over time. The cause of the decline in the Daily Temperature Range (DTR) in Queensland is unclear. From 1949-2000, DTR was lowest in Queensland during 1980 and this period was also characterized by lower than average rainfall.

This analysis demonstrated the use of time series and spectral method as an effective method for studying variations of temperature and rainfall data in that a cyclic nature of the two measures were found easily. The analysis of climatic data is valuable particularly to understand the complexity of the variations associated with global climate change. Clearly, the daily temperature and daily rainfall were not related directly, while DTR and rainfall were. Increases in DTR persist suggest lower rainfall and if this trend is then taken over time then that is not predicted by the literature on climate change. A multivariate and dynamic correlation technique may be useful here and this will be the focus of the first author's future research (Ismail et al., 2009).

\section{REFERENCES}

Abdullah, S., C.K.E. Nizwan and M.Z. Nuawi, 2009. A study of fatigue data editing using the ShortTime Fourier Transform (STFT). Am. J. Applied Sci., 6: 565-575. http://www.scipub.org/fulltext/ajas/ajas64565575.pdf

Bureau of Meteorology, 2005. Melbourne's unprecedented weather "much more than four seasons in one day, Melbourne, Bureau of Meteorology.

http://www.bom.gov.au/announcements/media_r eleases/vic/20050203.shtml

Bureau of Meteorology, 2002. Drought and rainfall history in Australia. Bureau of Meteorology. http://www.warwickhughes.com/drought/

Bureau of Meteorology, 1995 Annual climate summary/prepared by climate analysis section, National Climate Centre. Bureau of Meteorology. http://catalogue.nla.gov.au/Record/984015?lookf or=subject:\%22Australia\%20-

$\%$ 20Periodicals. \%22\&offset $=115 \& \max =35702$

Charnsethikul, P., 2007. Parallel approaches for intervals analysis of variable statistics in large and sparse linear equations with RHS ranges. Am. J. Applied Sci., 4: 300-306. http://www.scipub.org/fulltext/ajas/ajas45300306.pdf
Ismail, Z., A. Yahya and A. Shabri, 2009. Forecasting gold prices using multiple linear regression method. Am. J. Applied Sci., 6: 1509-1514. http://www.scipub.org/fulltext/ajas/ajas6815091514.pdf

Jones, P.D., P.Y. Groisman, M. Coughlan, N. Plummer and W.C. Wang et al., 1990. Assessment of urbanization effects in time series of surface air temperature over land. Nature, 347: 169-172. DOI: $10.1038 / 347169 \mathrm{a} 0$

Karl, T.R., P.D. Jones, R.W. Knight, G. Kukla and N. Plummer et al., 1993. A new perspective on recent global warming: asymmetric trends of daily maximum and minimum temperatures. Bull. Am. Meteorol. Soc., 74: 1006-1023. http://digitalcommons.unl.edu/cgi/viewcontent.c gi article $=1187 \&$ context $=$ natrespapers

Lough, J.M., 1991. Rainfall variations in Queensland, Australia: 1891-1986. Int. J. Climatol., 11: 745-768. DOI: 10.1002/joc.3370110704

Lough, J.M., 1993. Variations of some seasonal rainfall characteristics in Queensland, Australia: 1921-1987. Int. J. Climatol., 13: 391-409. DOI: 10.1002/joc.3370130404

Lough, J.M., 1995. Temperature variations in a tropical-subtropical environment: Queensland, Australia, 1910-1987. Int. J. Climatol., 15: 77-95. DOI: $10.1002 /$ joc.3370150109

Mantua, N.J. and S.R. Hare, 2002. The pacific decadal oscillation. J. Oceanogr., 58: 35-44. DOI: 10.1023/A:1015820616384

McKeon, G. and W. Hall, 2000. Learning from history: Preventing land and pasture degradation under climate change. Australian Greenhouse Office.

McKeon, G., W. Hall, B. Henry, G. Stone and I. Watson, 2004. Pasture degradation and recovery in Australia's rangelands: Learning from history. Queensland Government.

http://www.longpaddock.qld.gov.au/about/public ations/learningfromhistory/index.html

Nicholls, N. And B. Lavery, 1992. Australian rainfall trends during the twentieth century. Int. J. Climatol., 12 : 153-163. DOI: 10.1002/joc.3370120204

Pittock, A.B., 1975. Climatic change and the patterns of variation in Australian rainfall. Search, 6: 498-504.

Plummer, N., 1991. Annual mean temperature anomalies over eastern Australia. Bull. Aust. Meteorol. Oceanogr. Soc., 4: 42-44.

Plummer, N., Z. Lin and S. Torok, 1995. Trends in recent changes in the diurnal temperature range over Australia. Atmosph. Res., 37: 79-86. DOI: 10.1016/0169-8095(94)00070-T

Power, S., T. Casey, C. Folland, A. Colman and V. Mehta, 1999. Inter-decadal modulation of the impact of ENSO on Australia. Climate Dyn., 15: 319-324. DOI: $10.1007 / \mathrm{s} 003820050284$ 
Salinger, M.J., R.E. Basher, B.B. Fitzharris, J.E. Hay and P.D. Jones et al., 1995. Climate trends in the south-west Pacific. Int. J. Climatol., 15: 285-302. DOI: $10.1002 /$ joc. 3370150305

Singh, G. and E.A. Geissler, 1985. Late cainozoic history of fire, vegetation, lake levels and climate at Lake George, New South Wales, Australia. Philosop. Trans. R. Soc. Lond. B, Biol. Sci., 311: 379-447. http://www.jstor.org/pss/2398672

Sivakumar, M.V.K. and N. Ndegwa, 2007. Climate Change and Land Degradation. 1st Edn., Springer, New York, pp: 650.

Suppiah, R. and K.J. Hennessy, 1996. Trends in the intensity and frequency of heavy rainfall in tropical Australia and links with the Southern Oscillation. Aust. Meteorol. Mag., 45: 1-18. http://www.bom.gov.au/amm/docs/1996/suppiah. pdf
Tularam, G.A. and M. Ilahee, 2010. Relationship between EL NINO southern oscillation index and rainfall. Int. J. Sustain. Dev. Plann., 1: 1-14.

Whetton, P.H., A.M. Fowler, M.R. Haylock and A.B. Pittock, 1993. Implications of climate change due to the enhanced greenhouse effect on floods and droughts in Australia. Climate Change, 25: 289-317. DOI: 10.1007/BF01098378

Whetton, P.H., P.J. Rayner, A.B. Pittock and M.R. Haylock, 1994. An assessment of possible climate change in the Australian region Based on an intercomparison of general circulation modelling results. J. Climate, 7: 441-464. http://www.vsamp.com/resume/publications/Wh etton_et_al.pdf 